\title{
CARBON MONOXIDE UPTAKE AND PULMONARY DIFFUSING CAPACITY IN NORMAL SUBJECTS AT REST AND DURING EXERCISE ${ }^{1}$
}

\author{
By GILES F. FILLEY, DONALD J. MAcINTOSH, AND GEORGE W. WRIGHT \\ (From the Department of Physiology, the Trudeau-Saranac Institute, Trudeau, New York)
}

(Submitted for publication December 7, 1953; accepted December 23, 1953)

It is generally accepted that the exchange of pulmonary gases between "alveolar air" and pulmonary blood takes place by simple diffusion across the "pulmonary membrane." 2 Two properties of this membrane, namely, its permeability to gases and its surface area, are of considerable interest since a decrease in either could limit the rate of gaseous diffusion. There is no known physiological method for measuring specifically the permeability as contrasted to the area of the pulmonary diffusing surface in man. In 1915, M. Krogh (1), using carbon monoxide, made the first determinations of the pulmonary "diffusion constant" in human beings. This constant was considered to be proportional to both permeability and area of the diffusing surface and was expressed in cc. of $\mathrm{CO}$ diffusing per $\mathrm{mm}$. $\mathrm{Hg}$ of $\mathrm{CO}$ partial pressure difference on either side of the pulmonary membrane. Roughton (2) has viewed the diffusion constant of normal persons as a measure of the number and size of patent pulmonary capillaries. Several investigators (3), in considering the diffusion constant for oxygen, have recommended that it be referred to as the "diffusing capacity" because its magnitude is greater during exercise than at rest.

Carbon monoxide is peculiarly suitable for studies of gas diffusion across the pulmonary membrane because of the tenacity with which it is bound by hemoglobin after it has diffused into the red cells. For this reason, $\mathrm{CO}$ is taken up from respired gas for considerable periods of time (4) without there being a significant change in the Pco, or "escaping tendency," in the pulmonary capillary blood. The driving force responsible for CO transport across

1 These studies were aided by a contract between the Office of Naval Research, Department of the Navy, and the Trudeau Foundation (NR 112-214).

2 The "pulmonary membrane" refers to all the tissue and fluid barriers interposed between the gas phase of the lungs and the hemoglobin within the red cells. the pulmonary membrane can, therefore, be considered to be equal to the partial pressure of $\mathrm{CO}$ in the alveoli. Forbes, Sargent, and Roughton (5) have used these facts to estimate the pulmonary diffusing capacity in man at rest during the steady state of $\mathrm{CO}$ uptake.

Neither the method of Krogh nor that of Forbes, Sargent, and Roughton is suitable for diffusion studies of diseased persons, especially during exercise, since these methods require voluntary interruption of the pattern of breathing and/or the obtaining of an "alveolar" sample of gas which may or may not be representative of the gas to which pulmonary blood is exposed. The low oxygen method developed by Lilienthal, Riley, Proemmel, and Franke (6) and by Riley, Cournand, and Donald (7) for determining $\mathrm{Do}_{2}$ overcomes these disadvantages and does not require the use of $\mathrm{CO}$. However, the clinical application of this method is limited by the strictness of the conditions required for the validity of the assumptions on which the method is based. The purposes of this paper are to describe a method for determining a diffusing capacity for $\mathrm{CO}$ which avoids the difficulties of direct alveolar gas sampling and is clinically applicable during exercise, and to present the results of studies carried out in a group of normal subjects breathing 0.1 per cent $\mathrm{CO}$ in air at rest and during exercise.

\section{METHODS}

For experiments during rest, the subject lay quietly on a bed for 20 minutes with an indwelling needle threaded into a radial or brachial artery. Breathing through a mouthpiece connected to a respiratory valve (dead space $85 \mathrm{cc}$.) and an open circuit, the subject then inspired 0.1 per cent $\mathrm{CO}$ in air $^{3}$ for six minutes. During the second minute, the expired gas was allowed to enter a Douglas bag (dead space $300 \mathrm{cc}$.) which was then emptied and

${ }^{8}$ Cylinders of this mixture were supplied by the Mine Safety Appliances Company, Pittsburgh, Pennsylvania. 
reconnected to the expiratory side of the circuit. During the fifth and sixth minutes, expired gas was collected so that a known number of expirations was admitted to the Douglas bag while $15 \mathrm{cc}$. of arterial blood were slowly withdrawn into a heparinized syringe. For exercise experiments, the subject walked on a motor-driven treadmill for a six-minute period at 3.0 or $3.5 \mathrm{mph}$., and on various grades. The same high velocity respiratory valve was used as in the resting studies. Air was breathed for the first two minutes, 0.1 per cent $\mathrm{CO}$ in air for the last four minutes of exercise. During the fifth and sixth minutes of the walk, expired gas and arterial blood were collected as in experiments at rest. When several exercise experiments were performed with a given subject, they were carried out on different days. The speed of walking was kept constant for a given subject; more severe stints of exercise were arranged by increasing the grade of the mill.

The volume of expired gas was determined and samples were analyzed in duplicate for $\mathrm{CO}$ by a spectrophotometric method (8) using samples of the inspired $\mathrm{CO}$ mixture as standards in the determination. Duplicate analyses were required to check within 5 per cent. Expired $\mathrm{O}_{2}$ and $\mathrm{CO}_{2}$ concentrations were determined in the Haldane apparatus and duplicates were required to check within 0.04 volume per cent. Arterial blood was analyzed in duplicate immediately after sampling for $\mathrm{O}_{2}$ and $\mathrm{CO}_{2}$ tension by a modification (9) of the Riley bubble technique (10). Agreement between duplicates within $6 \mathrm{~mm}$. $\mathrm{Hg}$ was required.

\section{CALCULATIONS}

The minute ventilation, M.V., was expressed in liters per minute at BTPS. The $\mathrm{CO}$ uptake, in cc. $\mathrm{CO}$ per minute, was calculated as $\dot{V}_{C O}=\dot{V}_{E}\left(F_{I_{C O}} \frac{F_{E_{N_{2}}}}{F_{I_{N_{2}}}}-F_{E}\right)$ where $\dot{V}_{E}$ is the total gas volume STPD expired per minute, $F_{I}$ and $F_{E}$ are gas concentrations in inspired and expired volumes, and the subscripts refer to the gases in question. The fraction of $\mathrm{CO}$ removed from respired gas was calculated as

$$
\mathrm{CO}_{\mathrm{F}}=\frac{\dot{\mathrm{V}}_{\mathrm{CO}}}{\dot{\mathrm{V}}_{\mathrm{E}} \mathrm{F}_{\mathrm{ICO}_{\mathrm{CO}}}\left(\mathrm{FE}_{\mathrm{N}_{2}} / \mathrm{F}_{\mathrm{I}_{2}}\right)-\mathrm{f} \cdot \mathrm{d} \cdot\left(\mathrm{F}_{\mathrm{I}_{\mathrm{CO}}}-\mathrm{F}_{\mathrm{ACO}}\right)},
$$

where $f$ is the respiratory rate, $d$ the external apparatus dead space and $\mathrm{FAcO}_{\mathrm{Aco}}$ the concentration of $\mathrm{CO}$ in alveolar gas. $\mathrm{CO}_{\mathrm{F}}$ can thus be defined as the cc. of $\mathrm{CO}$ taken up by the blood per cc. of $\mathrm{CO}$ actually entering the lungs and upper respiratory passages. ${ }^{4}$ The alveolar $\mathrm{CO}$ tension was calculated by using a form of the Bohr relation (12) or alveolar equation (see Appendix) and assuming that the alveolar $\mathrm{CO}_{2}$ tension, $\mathrm{PACO}_{2}$, is equal to the arterial $\mathrm{CO}_{2}$ tension, $\mathrm{PaCO}_{2}$. The equation used was

where

$$
P_{A C O}=(B P-47) \frac{F_{E_{C O}}-r F_{I_{C O}}}{1-r},
$$

$$
\mathrm{r}=\frac{\mathrm{PaCO}_{2}-\mathrm{PE}_{\mathrm{CO}_{2}}}{\mathrm{PaCO}_{2}}
$$

${ }^{4} \mathrm{CO}_{\mathrm{F}}$ is a ratio similar to the "percentage uptake of CO" as defined by Bates (11).
The ratio of the tidal volume $V_{T}$ to the physiological dead space $V_{D}$ was calculated as

$$
\mathrm{V}_{\mathrm{T}} / \mathrm{V}_{\mathrm{D}}=\frac{\mathrm{V}_{\mathbf{T}}}{\mathbf{r} \mathrm{V}_{\mathrm{T}}-\text { apparatus dead space }} .
$$

A diffusing capacity for $\mathrm{CO}$ was calculated as $\mathrm{D}_{\mathrm{co}}=\dot{\mathrm{V}}_{\mathrm{co}} /$ PAco. The alveolar $\mathrm{O}_{2}$ tension, the alveolar-arterial $\mathrm{O}_{2}$ tension difference and $\mathrm{Do}_{2}$ were calculated by the methods of Riley, Cournand, and Donald $(7,13)$.

\section{RESULTS}

Eleven individuals, ten male and one female, who were either healthy or had arrested minimal pulmonary tuberculosis, were the subjects for these studies (see Table I). It was found that after an initial 2 to 4 minute period of breathing 0.1 per cent $\mathrm{CO}$ in air the $\mathrm{CO}$ uptake and the fraction of $\mathrm{CO}$ removed from respired gas $\left(\mathrm{CO}_{\mathrm{F}}\right)$ became constant and remained so for at least another four minutes both at rest and during exercise. From measurements and analyses of expired gas and arterial blood collected during a steady state of $\mathrm{CO}$ uptake at rest, the data of Table II were calculated. In these subjects at rest, the $\mathrm{CO}$ uptake varied from 2.2 to $4.0 \mathrm{cc}$. per min., and the $\mathrm{CO}_{\mathrm{F}}$ from 0.416 to 0.614 . There was a tendency for both $\mathrm{CO}$ uptake and alveolar $\mathrm{P}_{\mathrm{Co}}$ to be proportional to the ventilation in a given subject. The ratio of the $\mathrm{CO}$ uptake to the alveolar $\mathrm{Pco}$, or $\mathrm{Dco}$, tended to remain fairly constant in a given subject studied on different occasions. The mean Dco in the subjects studied at rest was 16.9 .

TABLE I

The case material of the present study

\begin{tabular}{rcccc}
\hline \hline Case & Age & Sex & S.A. & $\begin{array}{c}\text { Total } \\
\text { lung } \\
\text { capacity }\end{array}$ \\
\hline $84^{*}$ & 37 & M & 1.84 & 6.66 \\
$1471 \dagger$ & 23 & M & 2.06 & 6.03 \\
$1376 \dagger$ & 27 & M & 2.02 & 7.49 \\
$1363 \dagger$ & 33 & M & 1.84 & 5.34 \\
$1448 \dagger$ & 27 & M & 2.03 & 6.76 \\
$1450^{*}$ & 28 & F & 1.61 & 4.90 \\
$90 \dagger$ & 45 & M & 2.07 & 6.10 \\
$1286^{*}$ & 34 & M & 2.06 & 7.68 \\
$1368^{*}$ & 31 & M & 1.56 & 5.81 \\
$1439^{*}$ & 36 & M & 1.95 & 6.93 \\
$1284^{*}$ & 20 & M & 1.72 & 5.91 \\
\hline
\end{tabular}

* Unilateral arrested pulmonary tuberculosis involving less than 2 sq. $\mathrm{cm}$. on a P-A roentgenogram in full inspiration.

$\dagger$ Normal.

¥ The total lung capacity, given in liters BTPS, was determined by a slight modification of the open circuit method of Darling, Cournand, and Richards (14). 
TABLE II

Date obtained in resting subjects three of whom were studied on several occasions

\begin{tabular}{|c|c|c|c|c|c|c|c|}
\hline Case & MV & $\begin{array}{c}\mathrm{O}_{2} \\
\text { uptake }\end{array}$ & $\begin{array}{c}\text { CO } \\
\text { uptake }\end{array}$ & $\mathrm{CO}_{\mathrm{F}}$ & $P_{A C O}$ & $\frac{V_{T}}{V_{D}}$ & $\mathrm{D}_{\mathrm{co}}$ \\
\hline & L./min. & $L . / \min$. & cc. $/ \min$. & & $m m . H g$ & & $\begin{array}{c}c c . / \min . / \\
m m . H g\end{array}$ \\
\hline $\begin{array}{r}84 \\
84 \\
84 \\
84 \\
1471 \\
1376 \\
1376 \\
1363 \\
1448 \\
1448 \\
1450 \\
90\end{array}$ & $\begin{array}{r}10.9 \\
9.2 \\
6.3 \\
7.1 \\
8.5 \\
9.6 \\
7.4 \\
8.0 \\
5.9 \\
5.8 \\
7.0 \\
7.3\end{array}$ & $\begin{array}{l}.312 \\
.362 \\
.317 \\
.270 \\
.245 \\
.205 \\
.258\end{array}$ & $\begin{array}{l}3.3 \\
3.1 \\
2.4 \\
2.7 \\
3.1 \\
4.0 \\
3.1 \\
2.8 \\
2.2 \\
2.4 \\
2.3 \\
2.8\end{array}$ & $\begin{array}{l}.416 \\
.456 \\
.565 \\
.560 \\
.540 \\
.575 \\
.614 \\
.500 \\
.525 \\
.590 \\
.488 \\
.550\end{array}$ & $\begin{array}{l}.165 \\
.170 \\
.134 \\
.128 \\
.159 \\
.141 \\
.118 \\
.206 \\
.209 \\
.160 \\
.177 \\
.210\end{array}$ & $\begin{array}{l}2.4 \\
2.8 \\
3.8 \\
3.6 \\
4.0 \\
3.9 \\
4.4 \\
4.1 \\
4.7 \\
4.8 \\
3.5 \\
5.8\end{array}$ & $\begin{array}{l}19.8 \\
18.0 \\
17.8 \\
20.9 \\
19.3 \\
28.0 \\
26.3 \\
13.6 \\
10.5 \\
14.8 \\
13.0 \\
132\end{array}$ \\
\hline
\end{tabular}

The data obtained during exercise are shown in Table III. The stints of exercise were moderately severe involving 4 to 10 fold increases of $\mathrm{O}_{2}$ uptake over resting values. The $\mathrm{CO}$ uptake increased with increasing exercise and tended to follow both the minute ventilation and the $\mathrm{O}_{2}$ up- take. The fraction of $\mathrm{CO}$ removed from respired gas was considerably lower during exercise than at rest. Both PACO and $\mathrm{V}_{\mathbf{T}} / \mathrm{V}_{\mathbf{D}}$ were increased over resting values. The values for Dco varied from 23.2 to 55.0 among these subjects but in a given subject Dco remained approximately con-

TABLE III

Data obtained in normal subjects during treadmill exercise

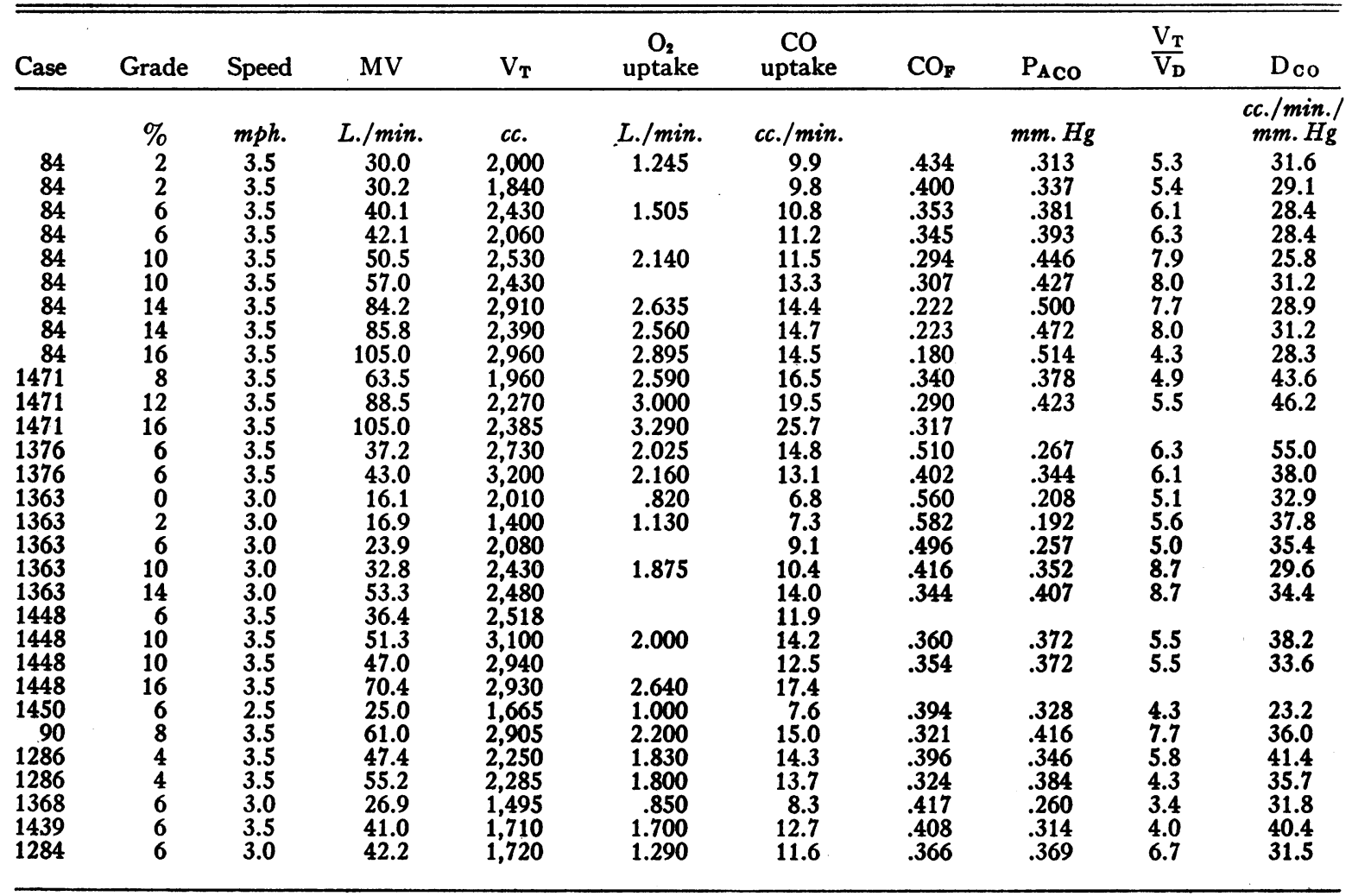



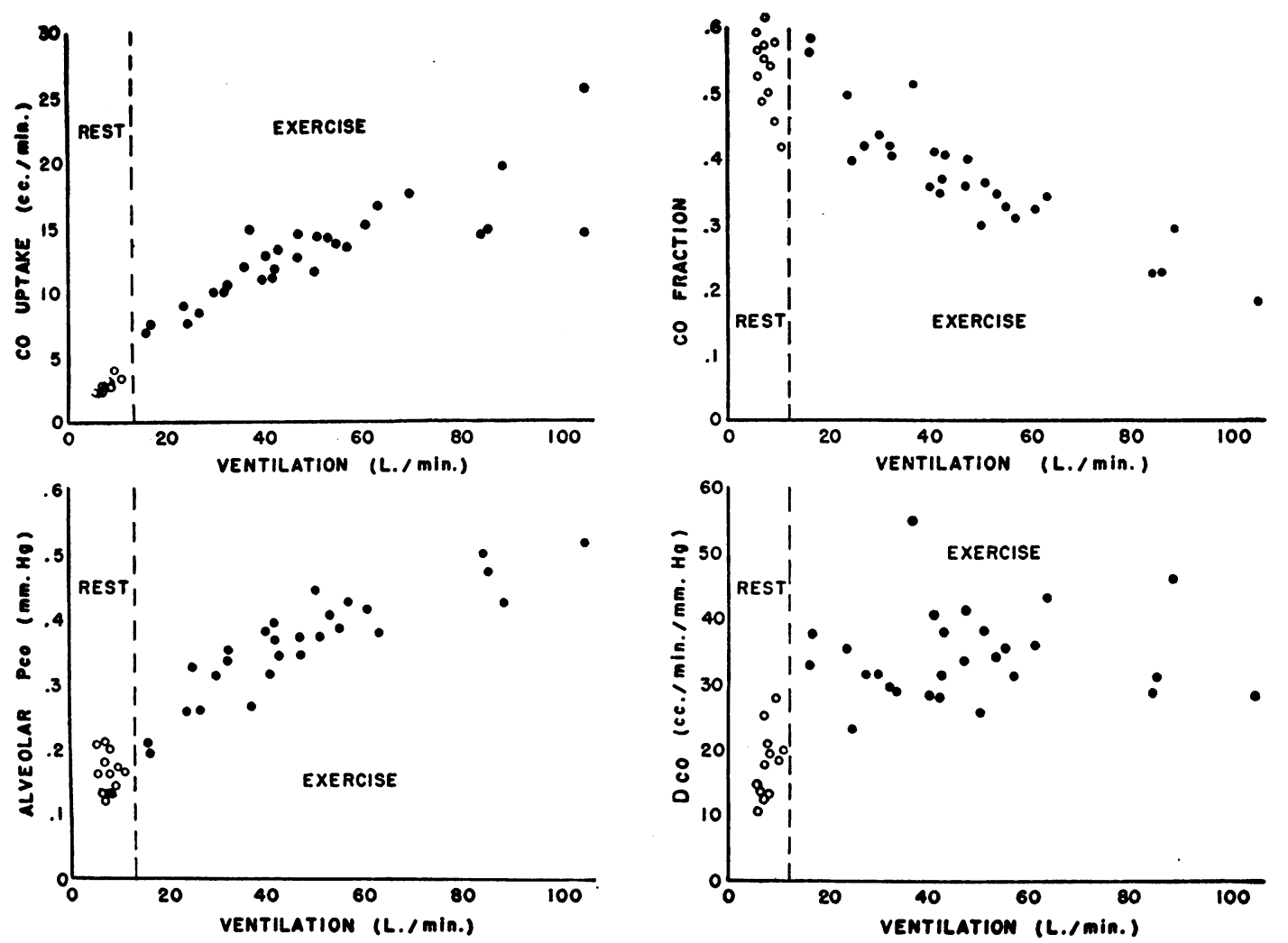

Fig. 1. The Relation of CO Uptake, CO, Paco and Dco to the Minute Ventilation in 11 Normal Subjects Breathing 0.1 Per Cent CO in Air

Six of the subjects were studied on several different days at various grades of exercise.

stant at various levels of exercise. The mean Dco in these 11 subjects during moderate exercise was 36.3.

All measurements of $\mathrm{CO}$ uptake, $\mathrm{CO}_{\mathrm{F}}, \mathrm{PACO}$, and $\mathrm{D}_{\mathrm{co}}$ obtained in these studies are plotted against the minute ventilation in Figure 1 . The CO uptake increased in an approximately linear fashion with the ventilation during the lower grades of exercise; at the higher grades the $\mathrm{CO}$ uptake was less closely related to the ventilation. The fraction of $\mathrm{CO}$ removed from respired gas decreased with increasing exercise while the alveolar Pco increased. Dco, having increased to about twice its resting value at moderate grades of exercise, showed no significant tendency to increase further with the augmented ventilation of the more severe grades of exercise.

\section{DISCUSSION}

The rate of $\mathrm{CO}$ uptake in men breathing low concentrations of $\mathrm{CO}$ ( 0.01 to 0.2 per cent in air) has previously been measured $(4,5,15)$ by methods based on analyses of inspired gas and venous blood and determinations or estimations of the blood volume. It has been found that under these conditions the $\mathrm{CO}$ uptake remains constant until the blood is approximately one-third saturated with CO. Three empirical formulae for predicting the increase in per cent $\mathrm{COHb}$ have been derived from such data.

In the present studies, the $\mathrm{CO}$ uptake was determined from the volumes and $\mathrm{CO}$ concentrations of inspired and expired gas, both concentrations being measured by the same analytical technique. We have confirmed the finding that a steady state of $\mathrm{CO}$ uptake is maintained during the early minutes of exposure. In Table IV a comparison is made between the present measurements of $\mathrm{CO}$ uptake and the values calculated from the three formulae referred to above. When allowance is made for the differences in the methods used, the results are in fairly good agreement. 
TABLE IV

Comparison between the present measurements of $\mathrm{CO}$ uptake and values calculated using formulae and data from literature

\begin{tabular}{|c|c|c|c|c|c|}
\hline & & $\begin{array}{c}\text { Present } \\
\text { data* }\end{array}$ & $\begin{array}{c}\text { Forbes, } \\
\text { Sargent, and } \\
\text { Roughton (5) }\end{array}$ & $\begin{array}{c}\text { Lilienthal } \\
\text { and Pine (15) }\end{array}$ & $\begin{array}{l}\text { Pace, } \\
\text { Consolazio, } \\
\text { White, and } \\
\text { Behnke (4) }\end{array}$ \\
\hline Resting & $\left\{\begin{array}{l}\text { Minute ventilation STPD (L./min.) } \\
\text { cc. CO uptake/cc. CO per L. inspired }\end{array}\right.$ & $\begin{array}{l}5.93 \\
2.8\end{array}$ & $\begin{array}{l}6.0 \\
3.4\end{array}$ & $\begin{array}{l}5.93 \\
2.7\end{array}$ & $\begin{array}{l}5.93 \\
2.6\end{array}$ \\
\hline $\begin{array}{l}\text { Light } \\
\text { exercise }\end{array}$ & $\left\{\begin{array}{l}\text { Minute ventilation STPD }(L . / \text { min. }) \\
\text { cc. CO uptake/cc. CO per L. inspired }\end{array}\right.$ & $\begin{array}{r}19.9 \\
8.8\end{array}$ & $\begin{array}{r}18.0 \\
9.1\end{array}$ & & $\begin{array}{r}19.2 \\
7.9\end{array}$ \\
\hline $\begin{array}{l}\text { Moderate } \\
\text { exercise }\end{array}$ & $\left\{\begin{array}{l}\text { Minute ventilation STPD (L./min.) } \\
\text { cc. CO uptake/cc. CO per L. inspired }\end{array}\right.$ & $\begin{array}{l}34.3 \\
12.4\end{array}$ & $\begin{array}{l}30.0 \\
12.5\end{array}$ & & $\begin{array}{l}34.3 \\
14.8\end{array}$ \\
\hline
\end{tabular}

* The present data are means from Tables II and III. In using the prediction formulae of Forbes, Sargent, and Roughton and Lilienthal and Pine, the blood volume was assumed to be 5.7 liters and the CO capacity of blood to be 20 volumes per cent.

In determining $\mathrm{CO}$ uptake by the present method, the chief source of error is in the analysis for $\mathrm{CO}$ in expired gas. The analysis is known (8) to be accurate to about 2 per cent. We have found that the variation of $\mathrm{CO}$ uptake per liter of ventilation among normal individuals is greater than can be accounted for by analytical errors. Among other factors which could explain such variation are the rate of respiration and the dead space of the respiratory valve used. These factors have been taken into account by calculating $\mathrm{CO}_{\mathrm{F}}$ which designates the fraction of $\mathrm{CO}$ taken up by the blood from the respired gas which actually enters the lungs and upper respiratory passages during the respiratory cycle. The variation in $\mathrm{CO}_{\mathrm{F}}$ among normal individuals (Tables II and III) confirm the observation of Forbes, Sargent, and Roughton (5) that there are "slow" and "fast" absorbers of CO.

During increasingly severe grades of exercise, the fraction of $\mathrm{CO}$ removed from respired gas progressively decreases in a given subject (Table III) and in the subjects as a group (Figure 1). What may be the factors acting to limit $\mathrm{CO}_{\mathrm{F}}$ in this manner? From what is known of the intrapulmonary distribution of gases and the linear relationship between $\mathrm{CO}$ uptake and $\mathrm{CO}$ concentration of inspired gas (5), it is apparent that $\mathrm{CO}_{\mathrm{F}}$ could be limited during increasingly severe exercise either because there is a limit to the rate at which inspired gas can be brought to the alveolar spaces by alveolar ventilation, or a limit to the rate at which $\mathrm{CO}$ can diffuse from alveolar gas into pulmonary blood. The former rate is determined by the total ventilation and the ratio $V_{T} / V_{D}$ and would obviously be a limiting factor if the ratio
$\mathrm{V}_{\mathbf{T}} / \mathrm{V}_{\mathbf{D}}$ were to decrease with exercise. Actually, however, $V_{T} / V_{D}$ increased with increasing exercise so that the fraction of $\mathrm{CO}$ removed from respired gas is not limited by this factor. As seen in Table III, however, the rate at which $\mathrm{CO}$ diffuses per $\mathrm{mm}$. $\mathrm{Hg}$ of alveolar $\mathrm{CO}$ tension in a given subject during moderate grades of exercise shows no appreciable tendency to increase as the grade of exercise increases. A relatively fixed $\mathrm{D}_{\mathrm{co}}$, therefore, appears to be a factor accounting for the decrease in $\mathrm{CO}_{\mathrm{F}}$, confirming deductions of Hatch (16).

These relationships can be visualized in Figure 1 where all $\mathrm{CO}$ measurements made on the 11 subjects of this study are plotted against the total ventilation. It is evident that whereas both $\mathrm{CO}$ uptake and alveolar Pco increase with the ventilation, the ratio between them bears no clear-cut relationship to the ventilation during exercise. The variation of Dco among normal individuals will be referred to later.

The ratio $D_{\text {co }}$ is affected not only by errors in the determination of the $\mathrm{CO}$ concentration of expired gas but also by errors in the analysis for arterial $\mathrm{PCO}_{2}$ from which alveolar Pco is calculated. An error in arterial $\mathrm{PCO}_{2}$ is particularly influential in affecting the resting value for Dco. In this laboratory, arterial $\mathrm{PCO}_{2}$ can be determined with an accuracy of $\pm 2 \mathrm{~mm}$. $\mathrm{Hg}$ (9). If a 2 per cent error in expired $\mathrm{CO}$ concentration is balanced by a $2 \mathrm{~mm}$. $\mathrm{Hg}$ error in arterial $\mathrm{PCO}_{2}$ in the same direction, Dco will be in error by less than 2 per cent both at rest and during exercise. However, if these errors are in opposite directions, the resting Dco may be 40 per cent higher or lower than the correct value. For conditions of exercise, analyti- 
cal errors in opposite directions produce about a 20 per cent error in Dco. Since these errors are of random character, it has been our custom to assign a probable error of 25 per cent for $D_{c o}$ at rest and 10 per cent for the value obtained under exercise conditions. In actual practice, as can be seen in Table II, the variation in Dco among normal subjects at rest is of the same order as that expected from analytical errors alone. For exercise conditions, however, not only are fairly reproducible values obtained for Dco in the same subject on different occasions, but the difference between subjects with respect to this measurement is greater than can be accounted for by such errors.

In addition to the effect of analytical errors on the value obtained for $\mathrm{Dco}$, it is necessary to consider the validity of this ratio as a measure of pulmonary diffusing capacity. As previously stated, the denominator of Dco, namely PAco, may be taken to be the head of pressure responsible for the measured rate of $\mathrm{CO}$ uptake. In examining this assumption, two factors of importance are: 1) Inequalities in actual $\mathrm{CO}$ tension in different parts of the lungs and different moments of the respiratory cycle; and 2) back pressure of $\mathrm{CO}$ in the pulmonary capillary blood resulting from failure of $\mathrm{CO}$ to react rapidly enough with red cell hemoglobin.

The present method for determining alveolar Pco is based on the concept elaborated by Riley, and Cournand (13) that alveolar gas composition can be defined by and indirectly calculated from measurements of expired gas tensions and the tension of $\mathrm{CO}_{2}$ in arterial blood. The alveolar Pco so calculated is a mean value which would exist uniformly in all alveoli if there were no temporal or spatial inequalities in alveolar $\mathrm{CO}$ tension. It is, therefore, an "effective" alveolar value in the same sense as the alveolar $\mathrm{Po}_{2}$ calculated by the method of Riley and his associates is "effective" (see Appendix). Forster (17) has concluded on theoretical grounds that the errors in these indirectly calculated alveolar values depend upon the magnitude of local variations in blood flow, diffusing capacity, ventilation and alveolar volume. Such errors may, therefore, be considerable in pathological subjects. In normal subjects, as has been shown elsewhere (18), the conditions required for the valid indirect calculation of $\mathrm{PAO}_{2}$ are closely approached, especially when the subjects are exercising. It is likely, therefore, that the present method of calculating PAco, which requires that the same conditions be fulfilled as in the oxygen studies, gives an alveolar $\mathrm{CO}$ tension to which pulmonary capillary blood is exposed when these conditions are met.

The possible influence of the rate of reaction of $\mathrm{CO}$ with hemoglobin in limiting the rate of $\mathrm{CO}$ uptake has been studied extensively by Roughton (19). He has calculated that "the average back pressure of $\mathrm{CO}$ in the blood is only of the order of 10 per cent of the alveolar pressure of CO" during $\mathrm{CO}$ breathing at rest and during hard work. If this figure is correct, the present values obtained for Dco would be about 10 per cent lower than the "true" CO diffusing capacity. Such a possible systematic error detracts little from the physiological usefulness of Dco since the extent to which it deviates from the "true" diffusing capacity is a function of the chemical nature of human blood and not of the structure of the lungs. Dco may therefore be considered, like the diffusion constant of Roughton (2), to be a ratio dependent upon the number of open alveolar capillaries, their length and radii, and the anatomical character of the tissues interposed between alveolar gas and alveolar capillary blood.

The evidence presented in this paper indicates that Dco rises during moderate exercise to values approximately twice those obtained at rest and that during increasingly severe exercise it remains constant in a given subject within the limits of experimental error. The cardiac output is known to increase with increasing grades of exercise. From previous evidence $(1,4)$, changes in linear rate of blood flow through pulmonary vessels should not affect $\mathrm{CO}$ uptake. The increased Dco during exercise is, therefore, explainable either on the assumption that the capillaries taking part in $\mathrm{CO}$ absorption increase in size or number or that the pulmonary membrane has changed in character under exercise conditions. The fact that Dco does not continue to increase with increasing exercise suggests either: a) That the capillary bed becomes fully expanded during moderate exercise and that there is no appreciable back pressure effect; or b) that the capillary bed continues to expand with increasing exercise and pari passu the back pressure effect becomes increasingly great. The former explanation is more likely since the back pressure effect can hardly increase with the 
increasing linear rate of pulmonary capillary flow which presumably occurs during heavy exercise when greater volumes of blood must flow through vascular channels that have reached their maximum size.

If such an increase in linear rate of capillary flow does in fact occur during heavy exercise, it may be that the back pressure of $\mathrm{CO}$ during moderate exercise is even less than that estimated by Roughton and that Dco determined under exercise conditions may, therefore, accurately measure the "true" diffusing capacity for $\mathrm{CO}$. If this is the case, and Krogh's (20) figures for the relative diffusibility of $\mathrm{CO}$ and $\mathrm{O}_{2}$ through animal tissues are accepted, then independent measurements of Dco and $\mathrm{DO}_{2}$ in the same subject under the same metabolic conditions should be related in the ratio of about 0.8 to 1.0. In Case No. 84, walking at $3.5 \mathrm{mph}$. on a 2 per cent grade, Dco was 31.6 and 29.1 (Table III). $\mathrm{Do}_{2}$, measured in the same subject on three occasions by the Riley, Cournand, and Donald method (7), was 30.0,32.0, and 29.3. These results and the data from which they were obtained are shown in Table V. It is believed that all the controllable conditions necessary for the valid application of this method were satisfied in these experiments. The fact that the $\mathrm{O}_{2}$ uptake consistently decreased when 15.65 per cent $\mathrm{O}_{2}$ was breathed is not understood but has been commonly observed to occur in this laboratory under resting conditions whether ventilation is controlled (21) or uncontrolled. It seems possible that in these three experiments the low $\mathrm{O}_{2}$ produced a change in the pulmonary vascular bed $(22,23)$ so that all the conditions necessary for the valid calculation of $\mathrm{Do}_{2}$ may not have been satisfied.

TABLE V

Three determinations of $\mathrm{D}_{\mathrm{O}_{2}}$ in case No. 84 performed on different days using the methods of Riley, Cournand, and Donald $(7,13)$

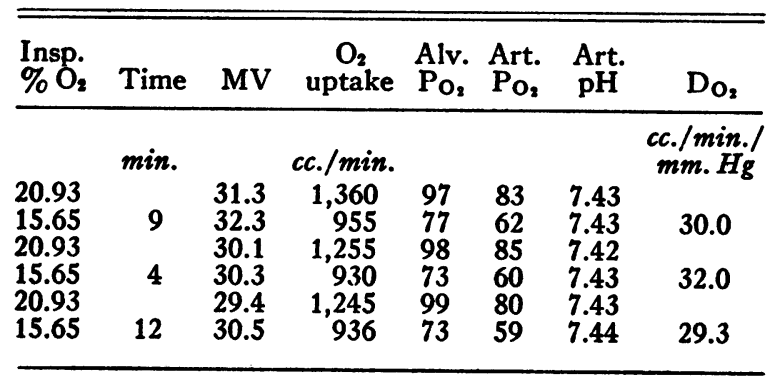

Since $\mathrm{Dco}_{\mathrm{C}}$ and $\mathrm{DO}_{2}$ are about equal in Case No. 84, it follows from Krogh's data that if Dco correctly measured $\mathrm{CO}$ diffusing capacity, $\mathrm{Do}_{2}$ underestimated the diffusing capacity for $\mathrm{O}_{2}$ in this subject. It may be that the underestimate resulted from the effects of low $\mathrm{O}_{2}$ tension on the pulmonary vasculature. From theoretical considerations, it is also possible that such an underestimate could result from the subject's not being studied at a high enough work level to ensure that all the blood in the alveolar capillaries participated in $\mathrm{O}_{2}$ uptake during all the time it was exposed to alveolar gas. Under these circumstances, the total "diffusion gradient" (7), though lower than during a heavier grade of work, would be less reduced than the quantity of $\mathrm{O}_{2}$ diffusing per minute so that a low $\mathrm{Do}_{2}$ could result. In other words, the exercise conditions for Case No. 84 may have been severe enough to bring Dco to its maximum value but not enough to require that the entire length of all alveolar capillaries be actually involved in $\mathrm{O}_{2}$ uptake. In determining $\mathrm{Dco}$, it is not necessary to impose special exercise conditions to ensure that all alveolar capillary blood participates in $\mathrm{CO}$ uptake since this occurs even at rest.

The fact that Dco remains approximately constant during increasingly severe exercise indicates that it is a measure of the maximum diffusing capacity when the $\mathrm{O}_{2}$ uptake is about four times the resting value. From Krogh's ratio, the maximum $\mathrm{Do}_{2}$ for the 11 subjects of this report would be $36.3 \div 0.8=45.4$. As Roughton (24) has pointed out, such a figure is too low to account, by accepted diffusion theory, for $\mathrm{O}_{2}$ transfer across the pulmonary membrane during heavy exercise at high altitudes. At sea level, however, a $\mathrm{Do}_{2}$ of 45 is quite adequate in accounting for the recently reported (25) $\mathrm{O}_{2}$ uptakes of $3,000 \mathrm{cc}$. per min. at an arterio-venous $\mathrm{O}_{2}$ difference of 145 cc. per liter. Determinations of Dco while low $\mathrm{O}_{2}$ mixtures are breathed may aid in resolving the difficulties arising from theoretical considerations of the mechanism of $\mathrm{O}_{2}$ transport at high altitudes.

It remains to consider the possible reasons why the fraction of $\mathrm{CO}$ removed from respired gas at comparable ventilation rates during exercise is greater in some normal persons than in others. Case No. 84 (Table III) was a "slow" absorber compared to Case No. 1471. Forbes, Sargent, and Roughton (5), on the basis of similar observations 
at rest, have suggested that "a slow rate of $\mathrm{CO}$ absorption [at a given ventilation rate] correlates with a low ratio of tidal air to dead space and/or a low diffusion constant." Case No. 84 did not have a low ratio $V_{T} / V_{D}$ compared to Case No. 1471 but did have a relatively low Dco. Other factors which might be related to such differences in $\mathrm{CO}_{\mathrm{F}}$ at comparable ventilation rates are age, body size, lung volume, or tidal volume. Cases No. 1471 and No. 1376, both fast absorbers, were young men with body surface areas over two sq. $m$. Their total lung volumes (Table I) were, however, not unusually large nor were their tidal volumes during exercise. Case No. 1471 was the only athlete in the group studied, being a middle distance runner. It is interesting that his exercise Dco was well above the average of the group and that his $\mathrm{CO}_{\mathrm{F}}$ at a ventilation rate of 105 liters per min. was nearly twice that of Case No. 84. An explanation for these observed differences may be that normal men vary considerably in the area or permeability of the pulmonary membrane.

The use of the term "pulmonary diffusing capacity" is perhaps most appropriate when it refers to the maximum capacity of the pulmonary membrane to allow diffusion of gases to take place -a state achieved most naturally under the stress of physical exercise. The method described for determining Dco is especially suitable for exercise studies. Not only are the possible errors arising from back pressure of CO likely to be small when the linear rate of pulmonary capillary blood flow is large, but also, as Roughton (2) has observed, the influence of the physiological dead space on the calculated PAco becomes so small during exercise that errors in the determination of arterial $\mathrm{PCO}_{2}$ become almost negligible.

\section{SUMMARY}

The CO uptake has been measured in 11 normal subjects breathing 0.1 per cent $\mathrm{CO}$ in air under resting conditions and during increasingly strenuous stints of exercise. The fraction of CO removed from respired gas decreased progressively with increasing exercise.

A method for calculating alveolar $\mathrm{CO}$ tension has been developed. The ratio of the $\mathrm{CO}$ uptake to this alveolar tension has been designated as Dco. The mean Dco at rest was 16.9 in seven subjects.
During moderate exercise the mean Dco was 36.3 in 11 subjects.

The fraction of $\mathrm{CO}$ removed from respired gas at a given ventilation rate varied as much as 25 per cent among normal subjects during exercise. $D_{\text {co }}$ is considered to be important in accounting for this variation.

Dco showed no tendency to increase during increasingly strenuous exercise. When Dco is determined during exercise requiring an $\mathrm{O}_{2}$ uptake of at least four times the resting value, it is considered to represent the maximum diffusing capacity of the lungs. Dco is probably a measure of the number and size of the pulmonary capillaries available for pulmonary gas exchange and the permeability of the alveolar membrane.

\section{APPENDIX}

A form of the Bohr relation (12) or "alveolar equation" has been found useful in this laboratory because it is convenient for calculating an alveolar concentration of any gas which is being taken up by, or excreted from, pulmonary blood at a rate which bears a constant ratio to the $\mathrm{CO}_{2}$ output. The derivation of this equation involves the same three assumptions that have been made in deriving other alveolar equations $(13,26)$ since all these equations are algebraic statements of the same relationships. The derivation of the form used in this laboratory both for calculating alveolar $\mathrm{Pco}$ and alveolar $\mathrm{Po}_{2}$ follows:

Assumption 1. Expired gas $\mathrm{V}_{\mathrm{T}}$ is made up of a dead space component $\mathrm{V}_{\mathbf{D}^{\prime}}$ (including that of the respiratory apparatus) and an alveolar component $\left(V_{T}-V_{D^{\prime}}\right)$.

Assumption 2. The $\mathrm{CO}_{2}$ concentration of inspired gas is zero. For one expiration, then

whence

$$
\mathrm{VT} \mathrm{FE}_{\mathrm{CO}_{2}}=\left(\mathrm{VT}-\mathrm{VD}^{\prime}\right) \mathrm{FACO}_{2}
$$

$$
\frac{V_{D^{\prime}}}{V_{T}}=\frac{F_{\mathrm{ACO}_{2}}-F_{E_{\mathrm{CO}_{2}}}}{F_{\mathrm{ACO}_{2}}}
$$

Assumption 3. $\mathrm{V}_{\mathrm{D}}^{\prime}$ has the same volume for $\mathrm{CO}_{2}, \mathrm{O}_{2}$, and any other gas $\mathrm{x}$, which is absorbed by or excreted from pulmonary blood at a rate bearing a constant ratio to $\mathrm{CO}_{2}$ output during a given experimental period.

$$
\mathrm{VTFE}_{\mathrm{O}_{2}}=\left(\mathrm{VT}-\mathrm{VD}^{\prime}\right) \mathrm{F}_{\mathrm{AO}_{2}}+\mathrm{VD}^{\prime} \mathrm{FI}_{\mathrm{O}_{2}}
$$

whence

Let

$$
\frac{V_{D^{\prime}}}{V_{T}}=\frac{F_{O_{2}}-F_{\mathrm{AO}_{2}}}{F_{\mathrm{I}_{3}}-F_{\mathrm{A}_{3}}}
$$

$$
r=\frac{V_{D^{\prime}}^{\prime}}{V_{T}} \quad F_{A_{2}}=\frac{F_{O_{2}}-r F_{O_{2}}}{1-r} .
$$

Similarly, for gas $x$, a general alveolar equation can be derived:

$$
\begin{gathered}
V T F_{E_{\mathbf{x}}}=\left(V T-V D^{\prime}\right) F_{A_{\mathbf{x}}}+V_{D^{\prime}} F_{I_{\mathbf{x}}} \\
F_{A_{\mathbf{x}}}=\frac{F_{E_{\mathbf{x}}}-r F_{I_{x}}}{1-r} .
\end{gathered}
$$


For ordinary conditions of air-breathing when $\mathbf{R}_{\mathbf{E}}=$

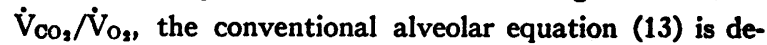
rivable from the general form given by equation (2) when a further assumption is made.

Assumption 4. Nitrogen is neither absorbed by, nor excreted from, the pulmonary blood so that total volume inspired $\times$ nitrogen fraction inspired $=$ total volume expired $\times$ nitrogen fraction expired or

or

$$
\dot{\mathrm{V}}_{\mathrm{IFI}_{\mathrm{N}_{2}}}=\dot{\mathrm{V}}_{\mathrm{EF}} \mathrm{E}_{\mathrm{N}_{2}}
$$

$$
\dot{\mathrm{V}}_{\mathrm{I}}-\dot{\mathrm{V}}_{\mathrm{E}}=\dot{\mathrm{V}}_{\mathrm{E}}\left(\frac{\mathrm{FE}_{\mathrm{N}_{2}}}{\mathrm{FI}_{\mathrm{N}_{2}}}-1\right)
$$

But if $\mathrm{CO}_{2}$ and $\mathrm{O}_{2}$ are being exchanged, the difference in volume between total inspired and expired gas is equal to the difference between the $\mathrm{O}_{2}$ uptake and the $\mathrm{CO}_{2}$ output:

$$
\begin{aligned}
\dot{\mathrm{V}}_{\mathrm{I}}-\dot{\mathrm{V}}_{\mathrm{E}}= & \dot{\mathrm{V}}_{\mathrm{O}_{2}}-\dot{\mathrm{V}}_{\mathrm{CO}_{2}} \\
= & \dot{\mathrm{V}}_{\mathrm{E}}\left(\mathrm{FI}_{\mathrm{O}_{2}} \frac{\mathrm{FE}_{\mathrm{N}_{2}}}{\mathrm{FI}_{\mathrm{I}_{2}}}-\mathrm{FE}_{\mathrm{O}_{2}}-\mathrm{FE}_{\mathrm{CO}_{2}}\right) \\
& =\frac{\dot{\mathrm{V}}_{\mathrm{CO}_{2}}\left(1-\mathrm{R}_{\mathrm{E}}\right)}{\mathrm{RE}_{\mathrm{E}}} .
\end{aligned}
$$

Rearranging equation (2) we get

$$
\mathrm{F}_{\mathrm{A}_{2}}=\mathrm{FI}_{\mathrm{O}_{2}}+\frac{1}{1-\mathrm{r}}\left(\mathrm{FE}_{\mathrm{O}_{2}}-\mathrm{F}_{\mathrm{O}_{2}}\right)
$$

Substituting from (5),

$$
\begin{aligned}
\mathrm{FAO}_{2}=\mathrm{FI}_{\mathrm{O}_{2}} & +\frac{1}{1-\mathrm{r}} \\
& \times\left(\mathrm{FI}_{\mathrm{O}_{2}} \frac{\mathrm{FE}_{\mathrm{N}_{2}}}{\mathrm{FI}_{\mathrm{N}_{2}}}-\mathrm{F}_{\mathrm{I}_{2}}-\mathrm{FE}_{\mathrm{CO}_{2}}-\frac{\dot{\mathrm{V}}_{\mathrm{I}}-\dot{\mathrm{V}}_{\mathrm{E}}}{\dot{\mathrm{V}}_{\mathrm{E}}}\right) .
\end{aligned}
$$

Substituting from (1) and (4),

$$
\begin{aligned}
F_{\mathrm{A}_{2}}= & \mathrm{Fl}_{\mathrm{O}_{2}}+\frac{\mathrm{F}_{\mathrm{ACO}_{2}}}{\mathrm{FE}_{\mathrm{CO}_{2}}} \\
& \times\left(\mathrm{F}_{\mathrm{O}_{2}} \frac{\dot{\mathrm{V}}_{\mathrm{I}}-\dot{\mathrm{V}}_{\mathrm{E}}}{\dot{\mathrm{V}}_{\mathrm{E}}}-\frac{\dot{\mathrm{V}}_{\mathrm{CO}_{2}}+\dot{\mathrm{V}}_{\mathrm{I}}-\dot{\mathrm{V}}_{\mathrm{E}}}{\dot{\mathrm{V}}_{\mathrm{E}}}\right) .
\end{aligned}
$$

Substituting from (5),

$$
F_{\mathrm{AO}_{2}}=F_{\mathrm{O}_{2}}+\frac{F_{\mathrm{ACO}_{2}}}{\dot{\mathrm{V}}_{\mathrm{CO}_{2}}}\left(F_{\mathrm{O}_{2}} \frac{\dot{\mathrm{V}}_{\mathrm{CO}_{2}}\left(1-R_{\mathrm{E}}\right)}{\mathrm{R}_{\mathrm{E}}}-\dot{\mathrm{V}}_{\mathrm{O}_{2}}\right)
$$

and by rearrangement, we obtain the conventional alveolar equation (12)

$$
\mathrm{FAO}_{\mathrm{A}_{2}}=\mathrm{FI}_{\mathrm{O}_{2}}+\frac{\mathrm{FACO}_{2} \mathrm{~F}_{\mathrm{I}_{2}}\left(1-\mathrm{R}_{\mathrm{E}}\right)}{\mathrm{R}_{\mathrm{E}}}-\frac{\mathrm{F}_{\mathrm{ACO}_{2}}}{\mathrm{R}_{\mathrm{E}}}
$$

Since equation (6) is also derivable (26) from the assumption that $R_{E}=R_{A}$, it follows that whenever $R_{\mathbf{E}}=\mathbf{R}_{\mathbf{A}}$, Assumption 3 is implicitly made, as Rahn (27) has demonstrated by means of the oxygen-carbon dioxide diagram. When more than two gases are being exchanged in a steady state such that during a given period of time the rate of absorption by or excretion from pulmonary blood of each gas bears a constant ratio to $\mathrm{CO}_{2}$ output (so that $R_{\mathrm{E}}=\frac{\dot{\mathrm{V}}_{\mathrm{CO}_{2}}}{\dot{\mathrm{V}}_{\mathrm{O}_{2}}}=\mathrm{R}_{\mathrm{A}}$ and $R_{\mathrm{E}^{\prime}}=\frac{\dot{\mathrm{V}}_{\mathrm{CO}_{2}}}{\dot{\mathrm{V}}_{\mathrm{X}}}=\mathrm{R}_{\mathrm{A}^{\prime}}$ ), the general equation (3) applies for each of these gases. This can be shown to follow algebraically from the fact that the complex form of the alveolar equation for $F_{A x}$ derived from an assumed equality between $R_{E^{\prime}}$ and $R_{\mathbf{A}^{\prime}}$ and containing both $R_{E}$ and $R_{E^{\prime}}$, reduces to equation (3).

\section{REFERENCES}

1. Krogh, M., The diffusion of gases through the lungs of man. J. Physiol., 1915, 49, 271.

2. Roughton, F. J. W., The average time spent by the blood in the human lung capillary and its relation to the rates of $\mathrm{CO}$ uptake and elimination in man. Am. J. Physiol., 1945, 143, 621.

3. Standardization of definitions and symbols in respiratory physiology. Federation Proc., 1950, 9, 602.

4. Pace, N., Consolazio, W. V., White, W. A., Jr., and Behnke, A. R., Formulation of the principal factors affecting the rate of uptake of carbon monoxide by man. Am. J. Physiol., 1946, 147, 352.

5. Forbes, W. H., Sargent, F., and Roughton, F. J. W., The rate of carbon monoxide uptake by normal men. Am. J. Physiol., 1945, 143, 594.

6. Lilienthal, J. L., Jr., Riley, R. L., Proemmel, D. D., and Franke, R. E., An experimental analysis in man of the oxygen pressure gradient from alveolar air to arterial blood during rest and exercise at sea level and at altitude. Am. J. Physiol., 1946, 147, 199.

7. Riley, R. L., Cournand, A., and Donald, K. W., Analysis of factors affecting partial pressures of oxygen and carbon dioxide in gas and blood of lungs: Methods. J. Applied Physiol., 1951, 4, 102.

8. Filley, G. F., Balfour, G. S., MacIntosh, D. J., Labelle, E., and Wright, G. W., A method for the determination of small quantities of carbon monoxide in air. To be published.

9. Filley, G. F., Gay, E., and Wright, G. W., The accuracy of direct determinations of oxygen and carbon dioxide tensions in human blood in vitro. J. Clin. Invest., 1954, 33, 510.

10. Riley, R. L., Proemmel, D. D., and Franke, R. E., A direct method for determination of oxygen and carbon dioxide tensions in blood. J. Biol. Chem., 1945, 161, 621.

11. Bates, D. V., The uptake of carbon monoxide in health and in emphysema. Clin. Sc., 1952, 11, 21.

12. Bohr, C., Ueber die Lunglenathmung. Skandinav. Arch. f. Physiol., 1891, 2, 236.

13. Riley, R. L., and Cournand, A., 'Ideal' alveolar air and the analysis of ventilation-perfusion relationships in the lungs. J. Applied Physiol., 1949, 1, 825.

14. Darling, R. C., Cournand, A., and Richards, D. W., Jr., Studies on the intrapulmonary mixture of gases. III. An open circuit method for measuring residual air. J. Clin. Invest., 1940, 19, 609.

15. Lilienthal, J. L., Jr., and Pine, M. B., The effect of oxygen pressure on the uptake of carbon monoxide by man at sea level and at altitude. Am. J. Physiol., 1946, 145, 346. 
16. Hatch, T. F., Carbon monoxide uptake in relation to pulmonary performance. Arch. Indust. Hyg. and Occup. Med., 1952, 6, 1.

17. Forster, R. E., Personal communication.

18. Filley, G. F., Gregoire, F., and Wright, G. W., Alveolar and arterial oxygen tensions and the significance of the alveolar-arterial oxygen tension difference in normal men. J. Clin. Invest., 1954, 33, 517.

19. Roughton, F. J. W., The kinetics of the reaction $\mathrm{CO}+$ $\mathrm{O}_{2} \mathrm{Hb} \rightleftharpoons \mathrm{O}_{2}+\mathrm{COHb}$ in human blood at body temperature. Am. J. Physiol., 1945, 143, 609.

20. Krogh, A., The rate of diffusion of gases through animal tissues, with some remarks on the coeffcient of invasion. J. Physiol., 1919, 52, 391.

21. Branscomb, B. V., and Wright, G. W., Effects of controlled low oxygen breathing upon exchange of respiratory gases in humans. Federation Proc., 1952, 11, 16.

22. Motley, H. L., Cournand, A., Werko, L., Himmelstein, A., and Dresdale, D., The influence of short periods of induced acute anoxia upon pulmonary artery pressures in man. Am. J. Physiol., 1947, 150, 315.

23. Hürlimann, A., and Wiggers, C. J., The effects of progressive general anoxia on the pulmonary circulation. Circulation Research, 1953, 1, 230.

24. Roughton, F. J. W., The diffusion constant of the lung. Am. J. M. Sc., 1944, 208, 136.

25. Asmussen, E., and Nielsen, M., The cardiac output in rest and work determined simultaneously by the acetylene and the dye injection methods. Acta physiol. Scandinav., 1952, 27, 217.

26. Handbook of Respiratory Data in Aviation, Committee on Medical Research, Subcommittee on Oxygen and Anoxia, Office of Scientific Research and Development, National Research Council, Washington, D. C., 1944.

27. Rahn, H., A concept of mean alveolar air and the ventilation-bloodflow relationships during pulmonary gas exchange. Am. J. Physiol., 1949, 158, 21. 